\title{
WPS3547
}

\section{Who Bears the Cost of Russia's Military Draft?}

\author{
Michael Lokshin and Ruslan Yemtsov ${ }^{1}$ \\ The World Bank
}

\begin{abstract}
In this paper we use data from a large nationally representative survey in Russia to analyze the distributional and welfare implications of the military draft. We focus on draft avoidance as a common response to highly unpopular conscription system ridden by corruption. We develop a simple theoretical model that describes household compliance decisions with respect to enlistment. We employ several econometric techniques to estimate the effect of various household characteristics on the probability to serve in the army and the implications for household income. Our results indicate that the burden of conscription falls disproportionately on the poor. Poor, low-educated, rural households are much more likely to have their sons enlisted compared to urban, wealthy and bettereducated families. The losses incurred by the poor are disproportionately large and exceed the statutory rates of personal income taxes.
\end{abstract}

$$
\text { JEL: D12, I32, J31 }
$$

Keywords: Military draft, distribution, public policy, Russia

\begin{abstract}
World Bank Policy Research Working Paper 3547, March 2005
The Policy Research Working Paper Series disseminates the findings of work in progress to encourage the exchange of ideas about development issues. An objective of the series is to get the findings out quickly, even if the presentations are less than fully polished. The papers carry the names of the authors and should be cited accordingly. The findings, interpretations, and conclusions expressed in this paper are entirely those of the authors. They do not necessarily represent the view of the World Bank, its Executive Directors, or the countries they represent. Policy Research Working Papers are available online at http://econ.worldbank.org.
\end{abstract}

\footnotetext{
${ }^{1}$ Michael Lokshin, mlokshin@worldbank.org, Development Research Group, Ruslan Yemtsov, ryemtsov@worldbank.org, Eastern Europe and Central Asia Poverty Reduction and Economic Management, both are at the World Bank, 1818 H Street NW, Washington, D.C., 20433, USA. We thank Martin Ravallion, Arijit Sen, Hanan Jacoby, and Waly Wane for useful suggestions and comments.
} 


\section{Introduction}

Each year approximately 400,000 young men between the ages of eighteen and twentyseven are drafted to serve two years in the Russian military forces. Although all young men in Russia have a duty under the law to perform military service, many manage to avoid it with less than 10 percent of eligible population actually being enlisted. Conscription is very unpopular in Russia and is perceived as a drag on household resources and human lives. Intuitively it is clear that such a system is prone to produce regressive outcomes, with rich shifting the burden to the poor, and the unfairness of the current conscription practices motivates to some extent ongoing debates on the military reform. A switch to a professional army is heralded by many opponents to the existing system as a preferred outcome on both efficiency and equity grounds. However, none of the arguments used so far in that polemics are informed by the rigorous economic analysis.

It is surprising how little is known about the economic effects of the military draft in Russia, given the interest in this subject in all strands of Russian society. There is not a single academic study known to us that covers that topic in Russia. This paper intends to fill this gap providing first empirical evidence on the distributional implication of military draft.

In that we rely on a body of literature dealing with the economic costs of conscription. Distributional implications of the draft system have not received much interest in the economic literature (Lau, Poutvaara and Wagener 2002). Most of the studies on that subject originated in the U.S. during the war in Vietnam, surrounded by public discussion leading to the reform of the system of military manpower procurement. Several of these studies focused mostly on labor market implications of the military service (e.g., Fisher 1969, Angrist 1990) and considered economic costs of the conscription as implicit tax (e.g., Hansen and Weisbrod 1967; Knapp 1973). One recent study analyzed the long-term impact of military service on human capital accumulation to evaluate economy-wide consequences of compulsory services within the general equilibrium framework (Lau, Poutvaara and Wagener 2002). Social capital aspects of draft are analyzed by Mulligan and Shleifer (2004) using the cross-country data. 
The interest in the economic consequences of the conscript practices is growing in the developing countries. Several recent studies address that issue in Latin American context (e.g., Cameron Dorleng and Torpe 2000 in Honduras; Meznar 1992 in Brazil). However, none of these studies investigates the distributional impacts of compulsory military service using micro-level data. Partly, that could be explained by the perception that military draft welfare losses are negligible compared to other factors influencing household well-being. Indeed, defense spending represents a small share of country budgets and military personnel costs are usually just a fraction of these spending. However, it is important to distinguish between the direct, intermediate burden of defense expenditures and the real costs to the society that could be large, long-term and fall disproportionately on the poor.

The difficulties of analyzing the distributional implications of military draft stem from the complexity of household reactions to the recruitment practices. Serving in the army is an important event that has multiple long and short-term implications for the liable individuals and their households. Such implications span across economic and noneconomic dimensions of well-being and affect different groups of population to a different degree. Anticipated enlistment kicks off a chain reaction affecting all dimensions of households life, well before the actual recruitment. The inferences based on direct comparisons of outcomes between the households with serving members and the rest of population will be biased. Identifying the effect of draft on the household imposes strict requirements on data. In most of the cases in the developing countries, we lack information about draftees' socio-economic background. Household surveys, on other hand, collect no information on the household members enlisted in the military ${ }^{2}$.

In this paper we develop a simple theoretical model that describes household compliance decisions with respect to military draft. This model motivates our empirical approach. We employ several econometric techniques to estimate the effect of various household characteristics on the probability to serve in the army and the draft-induced losses of household income. The analysis is based on the data from the large

\footnotetext{
${ }^{2}$ Using the standard definition of a household, the individuals absent from a household for an extended period of time are not counted as household members and no detailed information is collected on them.
} 
representative multi-topic household survey conducted by the Russia Statistical Agency in 2003.

Our results indicate that military service effects are not distributionally neutral. Poor, low-educated, rural households are more likely to have their sons enlisted compared to urban, wealthy and better-educated households. The losses incurred by the poor measured as a share of forgone wages in total household income are also disproportionately large. These losses are comparable in size to the income taxes currently existing in Russia. They potentially affect all households with male children at some point in their lifecycle.

Compulsory military service with non-universal enforcement is a typical feature of government policies in many developing economies. By explicitly linking the military draft with poverty observed at the household level this paper contributes to the broad debate on the effects of public policies on poverty. Forming military cadre through conscription is not widely regarded as an intervention that could have direct implications for poverty and inequality. Our paper is an attempt to attract attention of the research community interested in poverty and social impact analysis to this unduly overlooked domain.

The paper is organized as follows. Next section provides a description of the system of military personnel procurement in Russia. Section 3 gives details on the data, describes the main constructed variables used in the analysis, and contains a snapshot of the current incidence of military service with characteristics of draftees. We then follow in Section 4 with the development of the theoretical framework and empirical specifications to analyze the distributional implications of military service. Section 5 presents the main estimation results of household enlistment decision. Section 6 looks in depth on monetary costs of military service and Section 7 concludes. 


\section{Russian Military Service}

The Russian military currently have 1.2 million personnel staffed by mandatory conscripts and professional cadre ${ }^{3}$. The conscription is regulated by the Law on military service (GoR 1998). That law, while in principle retaining an obligation of all fit males between the ages of 18 and 27 to perform a military service (in force since 1919), introduced a number of exemptions and enabled alternative civil service. Exemptions are given based on medical conditions, to the full-time students of selected universities, and employees of certain organizations (e.g., police). Among the exempt are also the school teachers working in the rural areas, young husbands whose wives are 26 or more weeks pregnant, and young fathers of two or more children and of children under 3 years of age.

The number of draftees has been declining rapidly since mid-80s and it becomes increasingly difficult for Russian military recruitment offices to fill annual draft quotas. The latest report by the Russia Defense Minister indicates that armed forces drafted 30 percent of 18 to 27 year old males in the late 80 s and early 90 s. Only about 9.5 percent in that age group are planed to be conscripted in the fall of 2004. It coincided with the changes in Russia demographics with fewer and fewer young men coming to a conscription age (Hrustalev and Csumbal 2004).

The contraction in the number of conscripts outpaced the planed downsizing of the armed forces driven by the Russia military reform. Service in the army remains a feared duty to be avoided (through legal or illegal means) by the majority of Russian families. Serious abuses in the army are well known. Almost every day, news media reports stories on abysmal conditions in Russia army: Soldiers are often underfed and lack proper medical attention; first year draftees are abused by officers and second-year soldiers (the practice of hazing called "dedovshchina"), decaying equipment poses risks of serious injuries and death. Many young soldiers fear to be dispatched to Chechnya where ongoing conflict continues to claim lives. The desperation of the young soldiers leads to attempts to desert and to an increasing number of suicides. The military estimates that 2,500 to 3,000 soldiers desert the army every year (HRW 2002) and the number of

\footnotetext{
${ }^{3}$ Lately, in addition to conscripts, rank-and-file soldiers and sergeants are being staffed by contractualemployment, which still constitute a small minority of army personal (about 15,000 contract soldiers according to the MoD plans for 2004). Higher ranks were always made-up of professional soldiers.
} 
suicides exceeds the comparable statistics in armies of other European Countries and USA (MoD press release 2004).

Widespread aversion to military service makes the recruitment officers to rely on coercion in filling the draft quotas. The selective enforcement in enlisting young draftees leads to discriminatory outcomes in which the poor and unprotected fall victims. Many young men accused of dodging the country's mandatory draft are arrested by police and sent off to military bases. Police often abuse their authority to serve draft notices by illegally arresting conscription-age men. Legitimate exemptions are ignored, as are legal rights of appeal and even basic rights such as the ability to contact relatives. The well-off, on the other hand, often can avoid the draft through influence, bribery and other means.

\section{Data and descriptive profile of Russian conscripts}

One of the main difficulties of studying the effects of the military draft on household behavior is that the draft in Russia is relatively rare event affecting less then 10 percent of households with males 18 to 27 years of age. Household surveys of a standard sample size (4000-6000 households) would most likely miss such group completely, or collect information on a small sample of affected households that it would preclude any meaningful inferences ${ }^{4}$. The uniquely large NOBUS survey provides sufficient coverage and contains specific questions regarding enlistment.

Data for this study comes from Round I of the National Survey of Household Welfare and Program Participation (NOBUS) collected by the Russia State Statistics Service in collaboration with the World Bank. It was carried out in April and May 2003 and covered a sample of approximately 45,000 households and 118,000 individuals. NOBUS is a cross-sectional survey that uses a three-stage stratified sample design and is representative on the national, and on the regional level for 46 selected regions (GKS 2004).

NOBUS instruments resemble closely the questionnaires of the standard LSMStype survey. NOBUS gathers information about demographic characteristics of the

\footnotetext{
${ }^{4}$ For example, data from the latest (2003) round of the Russia Longitudinal Monitoring Survey contains information on 35 households with members in military and only 7 individuals ages 18 to 27 are reported to be drafted.
} 
household members, health, education, their main and secondary job activities, as well as individual sources of income and the amounts of wages, pensions and other social transfers. On the household level, the survey collects detailed data on different kinds of household expenditures, sources and amounts of household income, housing conditions, information on assets and home-production activities.

An important, for the purposes of the present study, feature of NOBUS is that it collects information (age, gender and the reasons of absence) about all household members who are absent from the household for more than three months. The households with individuals of the conscript age who were absent for the reason of the regular military service or draft comprise the core sample for our analysis. We are able to identify 466 households with individuals in the military service.

As the household welfare indicator we use the welfare ratios given by total household expenditure as a proportion of a household-specific poverty line. Total monthly expenditure includes household expenditures on food, clothing and foot-ware, expenditures on health, education, recreation, housing expenditures and utilities, flow of services from durables, and expenditures on miscellaneous goods and services.

We use the cost-of-basic-needs type poverty lines, that were developed based on the region-specific food prices to cost the age-gender specific food baskets necessary to meet dietary intake levels satisfying $\mathrm{WHO} / \mathrm{FAO}$ recommended daily caloric requirements (WHO 1985). In order to adjust for non-food expenditures the poverty line was scaled up by the coefficient that represents the average share of non-food expenditures of the household whose total food expenditures equal the food poverty line (Ravallion 1994) 5 .

Wages of the household members are calculated as a sum of monthly wages on the main and secondary job activities.

In our analysis we identify the population subject to conscription as able males 18 to 27 years of age. Table 1 shows the profile of males in the military service by age in full years. Overall, our data indicate that 5.1 percent of conscript-age males were in military service in 2003 (weighed estimate of 455,000 conscripts) ${ }^{6}$. These numbers correspond

\footnotetext{
${ }^{5}$ Detailed description of the algorithms for constructing household consumption aggregates and poverty lines see (Tesliuk and Sajaia 2004).

${ }^{6}$ The low proportion of 18 year olds in the military could be explained by the timing of the survey that was conducted just before or during the spring draft of 2003.
} 
well with the official Russian military statistics. For example, in the fall of 2004 Russian Defense Minister reported the result of semiannual conscription campaign announcing that 176,000 young males (of 9.5 percent of liable population) will be drafted into the two-year military service (Interfax 2004) ${ }^{7}$. According to the US-based Center for Defense Information (2004), around 400,000 young men between the ages of 18 and 27 are drafted each year to serve in one of the country's many branches of the armed forces. In addition to up to 80 percent of all eligible males who could be legally exempted from the service, approximately 30,000 dodge the draft each year (MK 2004).

Our data show that more than 90 percent of conscripts are younger than 23 years old. Almost 13 percent of 19 year olds males in our sample are in the military followed by 11.7 percent among 20 -year-old males. The proportion of conscripts decline with age and our data show no conscript military personnel older than 26 years old.

The likelihood to serve in the army varies with the household size (Figure 1). The lowest proportion of conscripts is registered among the smaller households. Less then 2 percent of sons in the families of single parent (usually a mother) are drafted. The probability of serving in the army reaches almost 8 percent for large households. Looking at the proportion of conscripts by the type of locality, the likelihood to be drafted is increasing almost monotonically for smaller size location. For example, young males living in Russia capital cities (Moscow and St. Petersburg) are almost 6 times less likely to be drafted compared with those from rural areas of Russia, where proportion of conscripts reaches 11 percent.

The military service should be evaluated against the background of economic opportunities that the conscripts have. Table 2 summarizes the descriptive statistics on the main labor market outcomes for the youth in draft-age group. Rates of labor force participation (LFP) are relatively low for the youngest (18 to 19 year old) but they increase sharply with age and reach over 70 percent for the men older than 22 . Similar to the LFP profile, wages increase with age and tenure. A new male entrant in the labor market earns roughly 50 percent less then the person with some labor experience. Military draft affects a large group of youth in their critical years of entry into the labor

\footnotetext{
${ }^{7}$ A discrepancy in the estimated proportion of draftees between MoD and NOBUS could arise from the different definitions of liable population.
} 
market and it distorts their working histories possibly leading to some losses of incomes over the entire work-life horizon. Next Section looks at how these losses are taken into consideration by the household as a decision-making unit.

\section{Theoretical framework and empirical strategy}

The presence of military draft affects economy-wide resource allocation. Compulsory military service inflicts direct short-term costs to households with male children. These costs could be associated with forgone market earnings of the conscripts and with the losses in the production of household-specific goods. Early economic studies, especially in the US, interpret these costs as implicit tax on household (e.g., Fisher 1969; Hansen and Weisbroad 1967). The hardship and risk of the military service could produce additional welfare losses for a draftee and members of his household. The long-term negative implications of the service are as important as the short-term costs. Empirical studies (e.g. Angrist 1991; Imbens and van der Klauw 1995) suggest that yearly costs to former conscripts could range between 5 and 15 percent of annual earnings over their lifetime. The impact of the military service on human capital formation could be a key cause for these losses.

Some countries attempt to introduce incentives that would motivate young men to enlist. Among such incentives are monetary compensations (stipends), training in marketable skills, tuitions credits and promotion of military service as patriotic duty. In the system of the compulsory service, as exists in Russia, soldiers receive negligible or zero monetary compensation. The military training obtained during the service is hardly transferable to civil occupations. Vanishing trust in the army and emerging divide between the military and the civil society means that the obligation to serve in the military is perceived as a burden and not as a duty even on moral grounds. ADD HERE

Induction to military service in Russia is not a predetermined, exogenous event. Trying to avoid conscription households engage into various activities reducing the risk of enlistments. The regulations leave a large room for discretion on behalf of public officials to decide who is going to serve in the army. That unavoidably leads to 
emergence of legal and illegal markets for draft-avoiding services ${ }^{8}$. The illegal ways to avoid conscription range from the bribery of medical doctors who ensure that the potential enlistees are labeled as unfit, to the existence of would-be universities that are created only on paper solely to provide exemptions from the army for their "students".

There are many efficiency and equity implications of the forced recruitment in the military service. If looked as a tax, the conscription induces efficiency losses. But in contrast with a tax the military draft is avoided by a majority of liable population and this produces inequitable distribution of such losses. To disentangle complex interactions of various factors that influence resource allocation decisions of the households subject to military draft we develop a simple theoretical model.

Consider a two-period, lifecycle economic model where parents make decisions about investments in the human capital of their children. The household gives up current consumption at period one for future utility flows that depend on the amounts invested in human capital. These investments begin to pay off during time period two.

Let the returns to human capital $H$ be denoted by $r$. Let $c_{h}$ be the per unit cost of inputs to the labor market human capital production function $f(H)$, with $f(H)$ '>0 and $f(H)^{\prime}$ " $<0$. Then, the amount spent on the production of labor market human capital is $c_{h} \cdot H$. Let the parent's current utility be given by $U_{t}\left(C_{t}\right)\left(\mathrm{U}_{t}{ }^{\prime}>0 ; U_{t}{ }^{\prime \prime}<0\right.$ for $\left.\mathrm{t}=1,2\right)$, where parents can give up some consumption $C_{l}$ for investments in their children's human capital ( $U_{2}$ is interpreted as a value function). We assume that the current endowments of the household are exogenous and given by $Y$, household is credit constraint, and household cannot save in period 1 to finance consumption in period 2. The formal optimization model facing the household in time period 1 is then:

$$
\begin{array}{ll}
\operatorname{Max} & U_{1}\left(C_{1}, X\right)+U_{2}\left(C_{2}, X\right) \\
\text { s.t.: } & C_{1}=Y-c_{h} \cdot H \\
& C_{2}=r \cdot f(H)
\end{array}
$$

Where $X$ is a household-specific vector of shift parameters of taste. The household chooses optimal level of investment in human capital $H^{*}$ that maximizes its utility. In this

\footnotetext{
${ }^{8}$ Prior to the introduction of the professional army in the Netherlands, for example, there were lawyers specializing service that would help to avoid military conscription, with clients willing to spend up to $\$ 2500$ to stay out of the military (Imbens and van der Klauw 1995).
} 
simple setup, where we consider only interior solutions $\left(C_{1}, C_{2}, H>0\right)$, the household demand for human capital is a function $H^{*}=H\left(r, c_{h}, Y, X\right)$.

We model the influence of the military draft on households with male children through its effects on human capital accumulation. Model (1) could be modified to take into account the losses in human capital associated with the military service. These losses $M$ are assumed to be a linear function of years spent in the army. In addition, we introduce a household-specific cost $B$ that is paid to avoid the conscription. Under these assumptions, the model of household decision about human capital investment could be presented as a choice between two regimes. In the first regime a household chooses to pay cost $B$ and avoid conscription, in the second, a household accepts the draft and the associated losses of human capital in the second period but does not bear the cost of $B$. The utility maximization problems for these two regimes could be expressed as:

$\operatorname{Max} U_{1}\left(C_{1}^{R}, X\right)+U_{2}\left(C_{2}^{R}, X\right)$ for $\mathrm{R}=1,2$

s.t.:

Regime 1 - pay cost, avoid draft : $\quad$ Regime 2 - pay nothing, get drafted :

$$
\begin{array}{ll}
C_{1}^{1}=Y-c_{h} \cdot H_{1}-B & C_{1}^{2}=Y-c_{h} \cdot H_{2} \\
C_{2}^{1}=r \cdot f\left(H_{1}\right) & C_{2}^{2}=r \cdot f\left(H_{2}-M\right)
\end{array}
$$

where $H_{1}$ and $H_{2}$ are the levels of human capital investment associated with two regimes. The existence of two regimes allows us to formulate the conditions under which a household is indifferent between draft and draft-avoidance. The examination of switching condition sheds light on household choices in the face of military conscription (See Annex 1 for details).

The FOC of (2) gives the household demand functions for $H_{1}$ and $H_{2}$ as $H_{l, 2}=H\left(r, c_{h}, Y, B, M, X\right)$. The household compares the values of the utility functions achieved at the optimum for the two regimes and selects the regime with the highest utility. The household prefers to pay a cost and avoid conscription (Regime 1) if $M \cdot c_{h}>B$, the household accepts to have its member enlisted if $M \cdot c_{h}<B$, and the household is indifferent between draft and avoidance if $M \cdot c_{h}=B$. Note that if $B>Y$ the household always chooses an enlistment Regime 2.

The intuition behind these switching conditions is fairly obvious. The higher is the cost of avoidance the less likely the household pays that cost and the more likely it is 
to yield to conscription. On the other hand, increasing losses from service reduce the probability of the household to select Regime 2. Higher costs of acquiring human capital increase the attractiveness of military service. Applying the implicit function theorem to the FOC, it is easy to demonstrate that under both regimes, the optimal level of human capital investment is lower than in the absence of military draft (Model 1).

This model gives several testable predictions. Given the relationship between Y and selection of the regime we would expect richer households to be more likely to avoid draft. Inter-household heterogeneity of draft-avoidance costs would also influence the likelihood of serving in the army. If, for example, the enforcement of conscription is location-specific, the households in low-enforcement areas will have lower probability of service compared with the similar households in the high-enforcement locations. The efficiency of transferring the accumulated human capital into the market returns, which could depend on individual characteristics of the potential draftees, would also affect the households choice of the regimes.

It is not unrealistic to assume that the utility losses due to the effects of military service differ across households and depend on household characteristics. For households with a single child liable for the military draft, a potential loss of human capital could have a stronger impact on the total welfare compared to the households with two sons. According to our model, the utility loss in period 2 resulting from death or serious injury of the enlisted single son moves households into part of the inter-temporal consumption space where the marginal utility of the period 2 consumption is high. That induces higher willingness to pay for draft-avoidance, other things being equal.

Our theoretical model guides the selection of the empirical estimation methods. The utility-comparison nature of the regime-switching process leads to the standard estimation setup. Switching conditions of equation (2) could be rewritten in the form:

$$
D^{*}=\left[U_{1}^{2}\left(C_{1}^{2}, X\right)+U_{2}^{2}\left(C_{2}^{2}, X\right)\right]-\left[U_{1}^{1}\left(C_{1}^{1}, X\right)+U_{2}^{1}\left(C_{2}^{1}, X\right)\right]
$$

where $D^{*}$ represents unobserved difference in utilities between the two regimes. We assume that $D^{*}$ has a positive lower bound as consumption approach to zero, and that $D^{*}$ is also bounded above as consumption approach infinity. The existence of the regime switching point $\left(D^{*}=0\right)$ in a general case follows from the Brouwer's fixed-point theorem given our boundedness conditions and as long as $D^{*}$ is continuous (e.g., Border 1985). 
Households make a marginal benefit-cost comparison based on utilities achieved in each regime. Household chooses Regime 1 if $D^{*} \leq 0$ and Regime 2 if $D^{*}>0$. Assuming that $D^{*}$ is linear in parameters (but possibly non-linear in variables) we can model the difference in the costs and benefits as an unobserved continuous variable $D^{*}$ such that:

$$
\begin{aligned}
& D_{i}^{*}=\beta \cdot X_{i}+\varepsilon_{i} \text { and } d_{i}=1 \text { if } \mathrm{D}_{i}^{*}>0 \\
& d_{i}=0 \text { otherwise }
\end{aligned}
$$

where $d_{i}$ is an indicator of the observed event of conscription, $X_{i}$ is a vector of household characteristics and $\varepsilon_{i}$ is an error term. If we assume that $\varepsilon_{i}$ is distributed normally, equation (4) could be estimated by the ordinary binary probit.

However, this estimation is complicated by the problem of endogeneity. Depending on the selected strategy, households adjust their behavior well in advance of the actual event of conscription. These adjustments could affect a broad spectrum of household characteristics including the labor market behavior and other income generating activities of the household members, the household long-term saving and asset accumulation decisions, and, obviously, the household income. Empirical specifications that include any such variables would produce biased estimates. In particular, the endogeneity precludes us from directly estimating the effect of the household income on the probability of conscription - one of the important issues of our analysis.

To account for the endogeneity of the household income we employ two strategies. First, we estimate the ordinary probit model including a set of assets ownership indicators that could proxy the household income prior to the conscription. We construct these indicators based on the information about assets purchased no later than two years before to the probable event of the military draft. We assume this lagged asset index is not directly affected by the conscription. The second strategy is based on the instrumental variable approach. We estimate the binary equation (4) jointly with the regression equation that instruments the current per capita consumption with the same assets index and asset ownership dummies we used in the first specification (further in the text we refer to this specification as IV probit model). Formally, this estimation algorithm could be expressed as the two-equation simultaneous model (e.g., Maddala 1983 p. 120): 


$$
\begin{array}{ll}
D_{i}^{*}=\gamma Y_{i}+\beta_{1} X_{1 i}+\varepsilon_{1 i} \text { where } & D_{i}^{*}=1 \text { if } d_{i}^{*}>0 \\
Y_{i}=\beta_{2} X_{2 i}+\varepsilon_{2 i} & d_{i}=0 \text { otherwise }
\end{array}
$$

and $\boldsymbol{X}_{1}$ and $\boldsymbol{X}_{2}$ are vectors of weakly exogenous variables. The identification conditions in this model are that disturbance terms $\varepsilon_{1}$ and $\varepsilon_{2}$ are independent, or else there is at least one variable in $\boldsymbol{X}_{1}$ that is not included in $\boldsymbol{X}_{2}$. Assuming that $\left(\boldsymbol{X}_{1}, \varepsilon_{1}, \varepsilon_{2}\right)$ are i.i.d., and $\varepsilon_{1}$ and $\varepsilon_{2}$ have, conditional on $\boldsymbol{X}_{1}$, a joint normal distribution with mean zero and positive definite covariance matrix, the system of equations (5) could be estimated by Full Information Maximum Likelihood method ${ }^{9}$.

\section{Estimation results}

We estimate the factors explaining the probability of the household to have its son drafted using binary and IV probit models. The estimations are based on the sample of 6126 households with male youth aged 18 to 27 in good health (group liable to serve in the army). The results of estimations are shown in Table 3.

The theoretical model of the previous section directs the selection of explanatory variables. They include the household demographic composition, educational levels of the adult members of the household, type of the locality the household resides in, and occupation of the household head. In the data we do not observe any characteristics of the draftees other then their age and the fact that they are currently serving in the military. Instead, we have to use some proxies for the individual characteristics of the enlisted men such as educational achievements of a household head and education profile of other household members. To reflect the difference in the local labor market conditions and in the systems of draft enforcement we use two constructed variables - the unemployment rate and proportion of the young males drafted in the locality ${ }^{10}$.

\footnotetext{
${ }^{9}$ Log-likelihood function for the system of system (4) is: $\ln L=\sum_{i} y_{1 i}\left(\ln \left[F\left(\eta_{i}\right)\right]+\ln \left[f\left(\eta_{i}\right)\right]\right)+\left(1-y_{1 i}\right)\left(\ln \left[1-F\left(\eta_{i}\right)\right]+\ln \left[f\left(\eta_{i}\right)\right]\right)$, where $F$ is a cumulative normal distribution function, $f$ is a normal density distribution function, $\rho$ is a correlation between $\varepsilon_{l}$ and $\varepsilon_{2}$, and $\eta_{i}=\left(\left(\beta_{1} x_{1 i}+\rho\left(Y_{i}-\beta_{2} x_{2 i}\right) / \sigma_{2}\right) / \sqrt{1-\rho^{2}}\right.$.

${ }^{10}$ These aggregate statistics are calculated based on the sample of about 150 households per each 79 locations. Our main estimation standard errors are not adjusted for the errors associated with these calculated statistics.
} 
Both binary and IV probit specifications give qualitatively similar results. The key link tested by these models is the effect of household income on the probability to serve. In the binary probit estimation, the household income is proxied by the lagged asset index. As predicted by our theoretical model, the effect is negative and significant. Other set of variables related to the household potential to generate income, - educational attainment of household members, - has even larger (and significant) coefficients. The larger is the share of highly educated adults in the household the less likely such household is to have its sons in the army. The IV probit estimation also indicates strong negative effect of the household consumption (instrumented by the assets ownership index) on the likelihood of military service. The effects of household members' education are similar to the coefficients of the binary probit estimations.

In line with predictions, households with a single son are much less likely to have him enlisted. The coefficients on the household size variables suggest the non-linear effect on the probability to serve. The probability is declining with size for the household with four or less members, and it increases for the larger households. A large share of prime-age males and females in the household as well as the share of pensioners has positive and significant effects on the probability to serve in the army.

Strong location effects picked up by the variable reflecting the regional share of youth serving in the army, reflects spatial differences in draft enforcement. This relationship holds even controlling for the labor market conditions in the region. In terms of our theoretical model, this implies that different regions are characterized by the different costs of draft-avoidance.

Similar to findings of the descriptive analysis of conscription, the estimation generates strong and significant correlation of the military draft incidence with the size of settlements. Males residing in the cities with population over 100,000 have much lower probability to be drafted compared to those living in smaller towns and villages. That probability is declining for the larger cities in both specifications.

Presence of professional military personnel in the family shows no statistically significant influence on the probability to serve. This may suggest that having their children enlisted as rank-and-file soldiers is not an attractive option even for the families of military officers. 
Other variables in the model introduced to mimic conscription rules, such as health conditions of other household members and single parent household indicator fail to produce any significant results.

We simulate the relationship between household wealth and the probability to serve in the army using the results of our estimations. Figure 2 is composed of three panels. All graphs indicate that wealthier households are less likely to have their sons conscripted. Top row graphs show the simulations for household with military service liable males. Graph on the left presents the predicted probability to be enlisted (using the IV probit estimates) as a function of per capita real consumption. The probability ranges from almost 20 percent for the lowest consumption percentiles to less then 3 percent for the richest households. The graph on the right is based on the alternative measure of household wealth, lagged asset index, and constructed using the ordinary binary probit estimates. It also demonstrates negative correlation between wealth and the likelihood of enlistment. However, the relationship is weaker than for the instrumented per capita consumption, which is not surprising given the noisiness of the asset index as a proxy of wealth.

In interpreting the results presented on these diagrams it is important to keep in mind that what we attempt to measure is the relationship between the enlistment and counterfactual consumption that the households with a drafted member would have had prior to the event of conscription. It is clear that ex ante household consumption is unobservable for all households with members of serviceable age, regardless of whether they were actually enlisted or avoided the draft. While we try to approximate this counterfactual consumption by instruments in the IV probit specification and by lagged asset index in the binary probit model, another way to explore the relationship between wealth and military service is to predict the probability of future military service for the households with sons of pre-draft age, i.e., 16 to 17 year old. For this group we can rely on their actual per capita consumption rather than proxies. Lowest panel of Figure 2 reports results of such simulation. This alternative route yields very similar results with the results reported above. Again, the poorest households have the highest probability to be enlisted and the richest households seem to be more likely to avoid the draft. 


\section{Monetary burden of the military draft}

Our theoretical model of Section 4 and the empirical estimations of the previous section give insights about which households attempt to avoid military service. We conceptualize the household decision-making by taking into considerations long-terms factors, such as human capital formation. In addition to the long-term burden, military service can have short-term welfare costs. On one hand, these costs could result from a wide spectrum of behavioral changes that households initiate in response to the event of conscription. On the other hand, the short-term welfare costs could be associated with the direct loss of wages due to the draft. We can simulate the immediate opportunity cost of a household member serving in the military as wages forgone due to being drafted (e.g., Hansen and Weisbrod 1967).

To quantify the differential burden of military service on the household wellbeing we need to estimate wages that the currently serving household members would earn have they avoided the draft. Such estimations are normally based on the models relating the individual characteristics with the labor market returns (e.g., Mincer type earning function). The survey we use collects only age data for the serving men. We miss critical information (an education level and tenure) necessary to obtain reliable wage predictions. Therefore, the wage estimates of such individuals would be imprecise.

To get around this problem, we adopt a strategy similar to one we used for ex ante consumption predictions in the previous section. We proceed in two stages. First, we estimate the selection-bias-corrected (Heckman 1978) earning functions for working young males for whom we observe wages and individual characteristics ${ }^{11}$. At the next stage, we turn our attention to pre-draft age males. Based on the estimated earning function we extrapolate the expected monthly wages for the males aged 16 to 17 to the point when they will reach the age of military service ${ }^{12}$. We also have information on their probability to serve in the army from the probit estimations. Combining these two results, we assess the expected current losses of monetary earnings from the conscription.

\footnotetext{
${ }^{11}$ We use household size, household demographic composition, assets ownership and regional unemployment rate as instruments in the selection equation.

${ }^{12}$ This interpolation is implemented by adding one year to the reported age of pre-draft males and assuming the completion of their education spell.
} 
The assumption that we make by using this group of households is that all their characteristics are very similar to the characteristics of the households with sons in a older age cohort. After all, the only difference between these two groups is that their sons are one year younger.

Formally, our simulation algorithm could be described as follows. Let $P_{w}($ Work $=1)$ be the probability to participate in the labor market, $P_{d}($ Serve $=1)$ be a probability to be drafted, and $E(w \mid$ Work $=1)$ be an expected conditional wage. Then the expected monthly wage losses due to the military service are:

$$
E(L)=P_{d}(\text { Serve }=1) \cdot P_{w}(\text { Work }=1) \cdot E(w \mid \text { Work }=1)
$$

Relating these wage losses to household consumption gives us a measure of welfare impact from the enlistment. As we argued above, a proper measure of a welfare burden should be constructed using not observed, but ex ante consumption. Since we limit our attention to the sample of households with pre-draft males, we assume that their actual consumption is not yet affected by the conscription ${ }^{13}$.

The relative importance of losses associated with conscription could be captured by the ratio of the expected forgone wages to the total household consumption. Wages of the new entrants to the labor market are usually low, but even these low wages can represent a substantial addition to the income of the households in poverty. A loss of these wages could push a household into a poverty trap. At the same time for wealthier households, this potential income source will be trivial.

Table 4 presents the selection-bias corrected estimation of the wage regression for the sample of males 18 to 26 years of age. The estimations produce sensible results. Expectedly, we observe strong locational wage effects. Controlling for age and education, youth living in villages earns lowest wages in comparison to the young males living in urban areas of Russia. Highest wages are registered in Moscow and Saint Petersburg. Older individuals, workers with longer tenure, and males with higher education earn higher wages. The level of labor force participation of young men is significantly affected

\footnotetext{
${ }^{13}$ Our approach neglects an important problem of a bias in wage estimation associated with the nonrandom (in terms of abilities and, correspondingly, of potential wages) characteristics of the conscripted individuals. In general, we cannot evaluate the direction of such bias, but, if, as our estimations show, the individuals with low prospects in the labor market are more likely to be conscripted, our wage estimates would be overstated for such men.
} 
by their age, educational and demographic composition of the household they live in, and by regional unemployment rate.

Results of this estimation are used to calculate expected forgone wages for the pre-draft age males. Multiplying these estimates by the probability to serve in the army according to (6) we obtain expected monthly wage losses due to the military service. Figure 3 shows the results. The estimated ratios range from the highest 50 percent to almost zero for the wealthiest households. The poor are disproportionately affected by such losses. On average, households below the poverty line (welfare ratio of 1 on the graph) experience about 15 percent loss in their per capita consumption due to the forgone wages as opposed to an average 6 percent for the households above the poverty line. Conceptualizing opportunity cost of military service as a tax we see, for the poor households, order of magnitudes similar to the rates of personal income taxes in Russia. Most important, such a tax is regressive as opposed to the flat 13 percent rate for the income tax. Although the military draft is not regarded as redistribution policy, the way it is implemented in Russia has profound distributional consequences.

\section{Conclusion}

In this paper we looked at the distributional implications of a peculiar system of military draft which prevails in many countries, but is not usually analyzed as an economic phenomenon. Such system combines formally universal requirements to serve in the army with lax enforcement so that the majority of potential conscripts avoid being drafted. Resulting distortions have strong efficiency and equity implications that are overlooked in the economic literature on development.

The theoretical model developed in the paper provides several testable hypotheses that were confirmed by our empirical results. We demonstrate that military draft has a number of negative consequences in terms of household well-being. Our simulations show that the burden of the military service is not negligible, amounting, on average, to 15 percent of household consumption. Rich household have more resources to evade the obligation to serve. Our estimates demonstrate that non-poor households in Russia are at least three times less likely to have their sons enlisted in the army than the poor. 
Therefore, losses associated with the military service disproportionately fall on the poor. Narrowly defined opportunity cost (expressed as lost wages) of military draft could be as high as 30 percent of a poor household per capita consumption.

Although we rely on Russian data, systems of involuntarily military procurement exist in many developing and transition economies. We think that households in these countries face similar choices and resulting misallocations could have important distributional and welfare implications. We claim that this area needs to be studied much more extensively. Theories of household behavior that incorporate long-term household decisions about strategies to cope with the cost of military service need to be developed. One of the major impediments for such research is the absence of data that would adequately capture both long and short-terms implications of the military draft and collect the information about histories of household members who served in the military. New data are required to better calibrate the magnitudes of the effects involved.

Our findings have broad policy implications. By demonstrating highly regressive features of discretionary enforced non-voluntary conscription into the military the paper suggests that poorly governed regulations may have large impact on the poor even tough at the first glance they seem to have no connection to redistribution policies. The key reason for such distortions could be the opportunity for corruption that opens ways for the rich to shift the burden of a costly obligation towards Government (such as an obligation to serve) on the poor.

One important area that we omitted in our paper is a gender dimension of welfare losses due to military draft. By distorting human capital formation decisions of the households with sons, conscription has general equilibrium effects on the demand for human capital of female children and may lead to even wider welfare losses. This can be a natural next step in the further development of the proposed model and its empirical applications. Another area of the proposed research agenda is related to simulations with a tax incidence model on the one hand to mimic the financing option for the volunteer army, combined with the cost incidence of the existing system that we covered in this paper.

Our findings have significant implications for the ongoing military reform in Russia. We show that the non-universal draft that exists in Russia is inferior to all- 
volunteer approach to military personnel procurement, not only on efficiency (as widely argued), but also, most importantly, on equity grounds. 


\section{Annex 1}

1. Optimization problem under "draft-avoidance" choice:

$\max U_{1}\left(Y-c_{h} H_{1}-B\right)+V_{2}\left(r \cdot f\left(H_{1}\right)\right.$

$H_{1}^{*}$ given by $: \frac{U_{1}^{\prime}\left(Y-c_{h} H_{1}^{*}-B\right)}{V_{2}^{\prime}\left(r \cdot f\left(H_{1}^{*}\right) f^{\prime}\left(H_{1}^{*}\right)\right.}=\frac{r}{c} ; \quad$ under strict concavity conditions $H_{1}^{*}$ is unique

Let $W_{1}^{*}=U_{1}\left(Y-c_{h} H_{1}^{*}-B\right)+V_{2}\left(r \cdot f\left(H_{1}^{*}\right)\right.$

2. Optimization problem under "draft" choice:

$\max U_{2}\left(Y-c_{h} H_{2}-B\right)+V_{2}\left(r \cdot f\left(H_{2}\right)\right.$

$H_{2}^{*}$ given by $: \frac{U_{1}^{\prime}\left(Y-c_{h} H_{2}^{*}-B\right)}{V_{2}^{\prime}\left(r \cdot f\left(H_{2}^{*}\right) f^{\prime}\left(H_{2}^{*}-2\right)\right.}=\frac{r}{c} ; \quad$ under strict concavity conditions $H_{2}^{*}$ is unique

Let $W_{1}^{*}=U_{1}\left(Y-c_{h} H_{2}^{*}-B\right)+V_{2}\left(r \cdot f\left(H_{2}^{*}-2\right)\right.$

Result 1:

Set $H_{2}=H_{1}^{*}+2$ then : $W_{2}^{*} \geq U_{1}\left(Y-c_{h} H_{2}\right)+V_{2}\left(r \cdot f\left(H_{2}-2\right)=\right.$

$$
=U_{1}\left(Y-c_{h} H_{1}^{*}-2 c_{h}\right)+V_{2}\left(r \cdot f\left(H_{1}^{*}\right)>W_{1}^{*}\right.
$$

Thus the "draft" choice is optimal is $2 \mathrm{c}_{\mathrm{h}}<\mathrm{B}$

Result 2:

Set $H_{1}=H_{2}^{*}-2$ then : $W_{1}^{*} \geq U_{1}\left(Y-c_{h} H_{1}-B\right)+V_{2}\left(r \cdot f\left(H_{1}\right)=\right.$

$$
=U_{1}\left(Y-c_{h} H_{2}^{*}-\left(2 c_{h}-B\right)\right)+V_{2}\left(r \cdot f\left(H_{2}^{*}-2\right)>W_{2}^{*}\right.
$$

Thus the "draft" choice is optimal is $2 \mathrm{c}_{\mathrm{h}}>\mathrm{B}$ 


\section{References}

Angrist, J. (1990) "Lifetime Earnings and the Vietnam Era Draft Lottery: Evidence from Social Security Administrative Records," American Economic Review, Vol. 80:313-36

Border, K., (1985), Fixed Point Theorems with Applications to Economics and Game Theory, Cambridge, UK: Cambridge University Press

Cameron, S., Dorling, G., and A. Thorpe (2000) "It Could Be You! Military Conscription and Selection Bias in Rural Honduras," European Review of Latin American and Caribbean Studies, Vol. 68: 47-63

Center for Defense Information (2004) "Russia: Rights Group Criticizes Draft Practices," CDI Russia Weekly, 232

Fisher, A., (1969) "The Cost of the Draft and the Cost of Ending the Draft," American Economic Review, Vol. 80: 239-53

Government of Russia (1998) Federal Law about Military Service, \#53-F3, Moscow GKS (2004) "Organizational and Methodological Principles of the National Survey of Household Welfare and Program Participation," Russian Federation State Statistical Committee, Moscow, http://www.worldbank.org.ru/ECA/Russia.nsf/

Hansen, W., and B. Weisbrod (1967) "Economics of Military Draft," Quarterly Journal of Economics, Vol. 81(3): 395-421

Heckman, J., Ichimura, H., and P. Todd, (1997), "Matching as an Econometric Evaluation Estimator: Evidence from Evaluating a Job Training Program," Review of Economic Studies Vol. 64(4): 605-654

Heckman, J., Ichimura, H., Smith, J., and P. Todd, (1998), "Characterizing Selection Bias using Experimental Data," Econometrica, Vol. 66: 1017-1099

Hrustalev, E, and B., Csumbal (2004) "Prognosis and analysis of socio-economic consequences of transition to the contract-based military organizations," Problems of prognosis, (Problemu prognozirovaniya), Vol. 4(85)

HRW (2002) "Conscription through Detention in Russia's Armed Forces," Human Research Watch Report, Vol. 14(8(D)), New York, NY (2003) "To Serve without Health? Inadequate Nutrition and Health Care in the Russian Armed Forces”, HRW Report, Vol. 15(9(D)), New York, NY

Imbens, G., and W. van der Klaauw (1995) "Evaluating the Cost of Conscription in the Netherlands," Journal and Business and Economic Statistics, Vol. 13(2): 207-15

Knapp, C., (1973) "A Human Capital Approach to the Burden of the Military Draft," Journal of Human Resources, Vol. 8(4): 485-96

Lau, M., Poutvaara, P., and A. Wagener (2004) “The Dynamic Cost of Military Draft," forthcoming in German Economic Review

Maddala, G., (1983) Limited-Dependent and Qualitative Variables in Econometric, Econometric Society Monographs No. 3, Cambridge University Press, New York

Meznar, J., (1992) "The Ranks of the Poor: Military Service and Social Differentiation in North-East Brazil, 1830-75," Hispanic American Historical Review, Vol. 72(3): 335-51

MK (2004) "Press-conference of the head of the enlistment office major-general V. Krasnogorski," Moskovskii Komsomolec, November 12, 2004, Moscow 
Mulligan, C., and A. Shleifer (2004) "Conscription as Regulation," Working paper \#10558, National Bureau of Economic Research, Cambridge, MA

Ravallion, M., (1994), Poverty Comparisons, Chur, Switzerland: Harwood Academic Press

Rubin, D., (1973) “The Use of Matched Sampling and Regression Adjustment to Remove Bias in Observational Studies." Biometrics Vol. 29: 159-183

Tesluk, E., and Z. Sajaia (2004) "XXXX", mimeo, The World Bank, Washington, DC

World Health Organization (1985), Energy and Protein Requirements, WHO, Technical Report Series 724, Geneva 
Table 1: Percent and the number of males age 18 to 27 in military service in Russia

\begin{tabular}{ccccc}
\hline $\begin{array}{c}\text { Age } \\
\text { in full years }\end{array}$ & $\begin{array}{c}\text { Percent } \\
\text { in military service }\end{array}$ & $\begin{array}{c}\text { Cumulative } \\
\text { percent }\end{array}$ & $\begin{array}{c}\text { Actual } \\
\text { observations }\end{array}$ & $\begin{array}{c}\text { Weighted } \\
\text { observations }\end{array}$ \\
\hline 18 & 3.26 & 9.87 & 46 & 38450 \\
19 & 12.78 & 38.20 & 132 & 142749 \\
20 & 11.65 & 65.24 & 126 & 125512 \\
21 & 8.75 & 84.55 & 90 & 84899 \\
22 & 3.60 & 93.35 & 41 & 37424 \\
23 & 1.74 & 97.00 & 17 & 16370 \\
24 & 0.74 & 98.93 & 9 & 6639 \\
25 & 0.37 & 100.00 & 5 & 3227 \\
26 & 0.00 & 100.00 & 0 & 0 \\
27 & 0.00 & 100.00 & 0 & 0 \\
Total & & & & 455270 \\
\hline \hline
\end{tabular}

Table 2: Labor market characteristics of male 18 to 26 in Russia

\begin{tabular}{ccccc}
\hline $\begin{array}{c}\text { Age } \\
\text { in full years }\end{array}$ & $\begin{array}{c}\text { Rate of labor force } \\
\text { participation }\end{array}$ & Log monthly wage & Years of Tenure & $\begin{array}{c}\text { Number of } \\
\text { observations }\end{array}$ \\
\hline 18 & 11.28 & 7.564 & 1.435 & 1,006 \\
19 & 17.98 & 7.688 & 1.584 & 1,015 \\
20 & 32.17 & 7.768 & 1.823 & 948 \\
21 & 46.31 & 7.864 & 2.033 & 850 \\
22 & 66.36 & 8.016 & 2.214 & 860 \\
23 & 71.77 & 8.117 & 2.449 & 801 \\
24 & 73.60 & 8.111 & 2.740 & 778 \\
25 & 76.41 & 8.136 & 3.253 & 724 \\
26 & 73.83 & 8.164 & 3.297 & 730 \\
& & & & \\
Total & 44.18 & 8.014 & 2.504 & 8.803 \\
\hline \hline
\end{tabular}


Table 2: Summary statistics for the main explanatory variables

\begin{tabular}{|c|c|c|}
\hline & Mean & Std. Deviation \\
\hline Per capita consumtion/100 & 2279.512 & 1604.326 \\
\hline Household size & 3.638 & 1.162 \\
\hline Household size2 & 14.588 & 10.118 \\
\hline Share of children $0-6$ years old & 0.036 & 0.097 \\
\hline Share of children $7-14$ years old & 0.035 & 0.090 \\
\hline Share of prime-age men & 0.168 & 0.144 \\
\hline Share of prime-age women & 0.231 & 0.145 \\
\hline Share of elderly & 0.028 & 0.096 \\
\hline Share of adults with primary education & 0.034 & 0.160 \\
\hline Incomplete secondary & 0.119 & 0.222 \\
\hline Complete secondary & 0.261 & 0.298 \\
\hline Technical vocational & 0.124 & 0.233 \\
\hline Secondary vocational & 0.259 & 0.296 \\
\hline Incomplete higher & 0.073 & 0.169 \\
\hline Complete higher and post-graduate & 0.130 & 0.239 \\
\hline Head with primary education & 0.039 & 0.180 \\
\hline Incomplete secondary & 0.098 & 0.297 \\
\hline Complete secondary & 0.220 & 0.414 \\
\hline Technical vocational & 0.111 & 0.314 \\
\hline Secondary vocational & 0.323 & 0.468 \\
\hline Incomplete higher & 0.031 & 0.173 \\
\hline Complete higher and post-graduate & 0.179 & 0.383 \\
\hline The son is a single child & 0.412 & 0.492 \\
\hline Single parent household & 0.182 & 0.386 \\
\hline Household members in the army & 0.014 & 0.119 \\
\hline Household members with bad health & 0.013 & 0.065 \\
\hline Moscow and Saint Petersburg & 0.033 & 0.179 \\
\hline Cities larger than $1 \mathrm{M}$ & 0.068 & 0.252 \\
\hline Cities 500,000-1M & 0.084 & 0.278 \\
\hline Cities 250,000-499,900 & 0.133 & 0.339 \\
\hline Cities $100,000-249,900$ & 0.105 & 0.307 \\
\hline Towns 50,000-99,900 & 0.074 & 0.261 \\
\hline Towns $20,000-49,900$ & 0.081 & 0.274 \\
\hline Towns with less than 20,000 , PGT & 0.139 & 0.346 \\
\hline Villages & 0.283 & 0.322 \\
\hline Share of young males in service ${ }^{\text {a) }}$ & 1.000 & 0.664 \\
\hline Regional unemployment rate & 0.143 & 0.093 \\
\hline Constructed assets index & 27.666 & 54.114 \\
\hline Household owns a car & 0.227 & 0.419 \\
\hline Household owns an AC & 0.012 & 0.111 \\
\hline Household owns a motobike & 0.079 & 0.269 \\
\hline Household owns a VCR & 0.442 & 0.497 \\
\hline Household has extra property & 0.307 & 0.461 \\
\hline
\end{tabular}

a) The regional share of male in service is normalized by the national average 
Table 3: Ordinary probit and IV probit estimations of the probability of the household to have its son in the military.

\begin{tabular}{|c|c|c|c|c|}
\hline & \multicolumn{2}{|c|}{ Binary probit } & \multicolumn{2}{|c|}{ IV Probit ${ }^{\text {a) }}$} \\
\hline & Coefficient & Std. Error & Coefficient & Std. Error \\
\hline Per capita consumtion/100 & & & $-0.184^{* *}$ & 0.059 \\
\hline Household size & $-0.186^{*}$ & 0.104 & $-0.308^{* *}$ & 0.105 \\
\hline Household size2 & $0.022^{*}$ & 0.011 & $0.030^{* *}$ & 0.01 \\
\hline Share of children $0-6$ years old & -0.719 & 0.452 & $-0.891^{*}$ & 0.432 \\
\hline Share of children $7-14$ years old & -0.487 & 0.302 & $-0.574^{*}$ & 0.288 \\
\hline Share of prime-age men & $0.917^{* *}$ & 0.263 & $0.932^{* * *}$ & 0.248 \\
\hline Share of prime-age women & $1.287^{* * *}$ & 0.237 & $1.158^{* * *}$ & 0.229 \\
\hline Share of elderly & $0.784^{*}$ & 0.370 & $0.639^{*}$ & 0.356 \\
\hline Share of adults with primary education & & Reference & & \\
\hline Incomplete secondary & $-0.910^{* *}$ & 0.265 & $-0.870^{* *}$ & 0.254 \\
\hline Complete secondary & $-1.378^{* * *}$ & 0.255 & $-1.183^{* * *}$ & 0.256 \\
\hline Technical vocational & $-0.698^{*}$ & 0.271 & $-0.621^{*}$ & 0.261 \\
\hline Secondary vocational & $-1.078^{* * *}$ & 0.264 & $-0.922^{* *}$ & 0.26 \\
\hline Incomplete higher & $-2.235^{* * *}$ & 0.348 & $-1.844^{* * *}$ & 0.37 \\
\hline Complete higher and post-graduate & $-1.414^{* * *}$ & 0.313 & $-1.146^{* *}$ & 0.322 \\
\hline Head with primary education & & Reference & & \\
\hline Incomplete secondary & 0.086 & 0.180 & 0.111 & 0.172 \\
\hline Complete secondary & $0.332^{*}$ & 0.175 & $0.299^{*}$ & 0.167 \\
\hline Technical vocational & 0.019 & 0.188 & 0.054 & 0.18 \\
\hline Secondary vocational & 0.278 & 0.178 & $0.288^{*}$ & 0.17 \\
\hline Incomplete higher & 0.477 & 0.285 & 0.448 & 0.27 \\
\hline Complete higher and post-graduate & 0.274 & 0.205 & 0.284 & 0.194 \\
\hline The son is a single child & $-0.644^{* * *}$ & 0.074 & $-0.620^{* * *}$ & 0.073 \\
\hline Single parent household & 0.043 & 0.087 & 0.021 & 0.083 \\
\hline Household members in the army & 0.015 & 0.205 & 0.023 & 0.194 \\
\hline Household members with bad health & -0.632 & 0.482 & -0.724 & 0.458 \\
\hline Moscow and Saint Petersburg & -0.308 & 0.260 & -0.310 & 0.251 \\
\hline Cities larger than $1 \mathrm{M}$ & $-0.251^{*}$ & 0.121 & $-0.264^{*}$ & 0.113 \\
\hline Cities 500,000-1M & $-0.270^{*}$ & 0.119 & $-0.244^{*}$ & 0.114 \\
\hline Cities 250,000-499,900 & $-0.281^{* *}$ & 0.094 & $-0.262^{* *}$ & 0.09 \\
\hline Cities $100,000-249,900$ & $-0.224^{*}$ & 0.099 & -0.149 & 0.101 \\
\hline Towns 50,000-99,900 & -0.175 & 0.111 & -0.107 & 0.111 \\
\hline Towns $20,000-49,900$ & -0.057 & 0.099 & 0.005 & 0.097 \\
\hline Towns with less than 20,000 , PGT & -0.077 & 0.082 & -0.031 & 0.082 \\
\hline Villages & & Reference & & \\
\hline Share of young males in service & $0.451^{* * *}$ & 0.049 & $0.406^{* * *}$ & 0.05 \\
\hline Regional unemployment rate & -0.233 & 0.396 & -0.510 & 0.387 \\
\hline Constructed assets index & $-0.002^{*}$ & 0.001 & & \\
\hline Household owns a car & 0.097 & 0.070 & & \\
\hline Household owns an AC & -0.161 & 0.337 & & \\
\hline Household owns a motobike & $0.165^{*}$ & 0.091 & & \\
\hline Household owns a VCR & $-0.123^{*}$ & 0.058 & & \\
\hline Household has extra property & -0.026 & 0.063 & & \\
\hline Constant & $-0.735^{*}$ & 0.330 & -0.047 & 0.386 \\
\hline Log-likelihood/Joint Log-Likelihood & -1408 & & -12030 & \\
\hline Number of observations & 612 & & 612 & \\
\hline
\end{tabular}

a) Estimated coefficients of instrumental regression are shown in Annex 2. 
Table 4: FIML Selection-bias corrected wage estimation. Wage regression and Selection probit estimates. Sample of males age 18-26.

\begin{tabular}{|c|c|c|c|c|}
\hline & \multicolumn{2}{|c|}{ Wage regression } & \multicolumn{2}{|c|}{ Selection probit } \\
\hline & Coefficient & Std. Error & Coefficient & Std. Error \\
\hline Age & $0.315^{\dagger}$ & 0.236 & $1.844^{* *}$ & 0.523 \\
\hline $\mathrm{Age}^{2}$ & $-0.007^{\dagger}$ & 0.005 & $-0.041^{* *}$ & 0.012 \\
\hline Primary education & & Reference & & \\
\hline Incomplete secondary & -0.139 & 0.183 & 0.486 & 0.404 \\
\hline Complete secondary & 0.097 & 0.178 & -0.328 & 0.395 \\
\hline Technical vocational & 0.035 & 0.179 & -0.413 & 0.410 \\
\hline Secondary vocational & 0.089 & 0.178 & 0.214 & 0.407 \\
\hline Incomplete higher & $0.434^{*}$ & 0.201 & $-1.024^{*}$ & 0.489 \\
\hline Complete higher and post-graduate & $0.363^{*}$ & 0.180 & -0.320 & 0.430 \\
\hline Tenure & $0.052^{*}$ & 0.026 & $0.209^{* *}$ & 0.062 \\
\hline Moscow and Saint Petersburg & $0.991^{* * *}$ & 0.080 & -0.134 & 0.294 \\
\hline Cities larger than $1 \mathrm{M}$ & $0.713^{* * *}$ & 0.073 & $-0.414^{*}$ & 0.202 \\
\hline Cities 500,000-1M & $0.737^{* * *}$ & 0.113 & 0.175 & 0.214 \\
\hline Cities 250,000-499,900 & $0.583^{* * *}$ & 0.079 & 0.094 & 0.174 \\
\hline Cities $100,000-249,900$ & $0.695^{* * *}$ & 0.095 & -0.170 & 0.184 \\
\hline Towns 50,000-99,900 & $0.520^{* * *}$ & 0.100 & 0.328 & 0.199 \\
\hline Towns $20,000-49,900$ & $0.482^{* * *}$ & 0.099 & 0.291 & 0.214 \\
\hline Towns with less than 20,000, PGT & $0.502^{* * *}$ & 0.093 & 0.104 & 0.195 \\
\hline Villages & & Reference & & \\
\hline Household size & & & 0.154 & 0.152 \\
\hline Household size2 & & & -0.015 & 0.015 \\
\hline Share of children 0-6 years old & & & 0.331 & 0.485 \\
\hline Share of children $7-14$ years old & & & -0.335 & 0.345 \\
\hline Share of prime-age men & & & $-1.200^{*}$ & 0.530 \\
\hline Share of prime-age women & & & $-1.199^{*}$ & 0.551 \\
\hline Share of elderly & & & 0.126 & 0.471 \\
\hline Share of adults with primary education & & Reference & & \\
\hline Incomplete secondary & & & -0.238 & 0.322 \\
\hline Complete secondary & & & $-0.879^{*}$ & 0.314 \\
\hline Technical vocational & & & -0.423 & 0.343 \\
\hline Secondary vocational & & & -0.357 & 0.320 \\
\hline Incomplete higher & & & $-1.010^{*}$ & 0.520 \\
\hline Complete higher and post-graduate & & & -0.459 & 0.330 \\
\hline Head with primary education & & Reference & & \\
\hline Incomplete secondary & & & 0.774 & 0.582 \\
\hline Complete secondary & & & $2.262^{* *}$ & 0.577 \\
\hline Technical vocational & & & $2.209^{* *}$ & 0.618 \\
\hline Secondary vocational & & & $1.581^{*}$ & 0.580 \\
\hline Incomplete higher & & & $2.990^{* *}$ & 0.917 \\
\hline Complete higher and post-graduate & & & $1.984^{* *}$ & 0.621 \\
\hline Share of employed household members & & & -0.302 & 0.264 \\
\hline Constructed assets index & & & 0.003 & 0.002 \\
\hline Household owns a car & & & $-0.485^{* *}$ & 0.125 \\
\hline Household owns an AC & & & -0.703 & 0.531 \\
\hline Household owns a motorbike & & & -0.246 & 0.185 \\
\hline Household owns a VCR & & & 0.193 & 0.113 \\
\hline Household has extra property & & & 0.113 & 0.111 \\
\hline Regional unemployment rate & & & $-2.231^{* * *}$ & 0.560 \\
\hline Constant & 3.563 & 2.594 & $-20.895^{* *}$ & 5.784 \\
\hline
\end{tabular}

Note: ${ }^{\dagger}$ indicate joint significance of the coefficients 


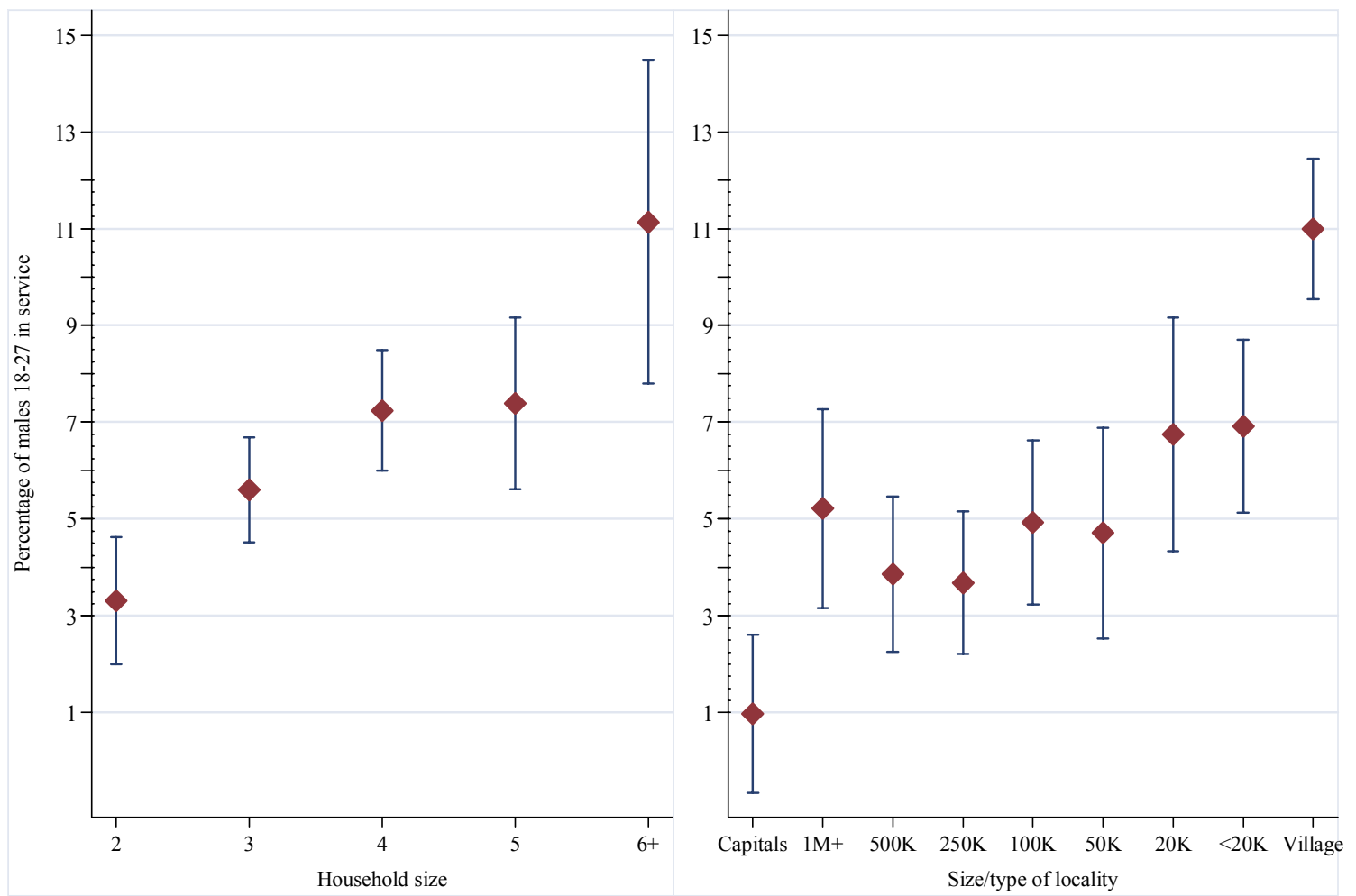

Figure 1: Proportion of males age 18 to 27 in compulsory military service by household size and type of locality. Mean and 95\% confidence interval. 

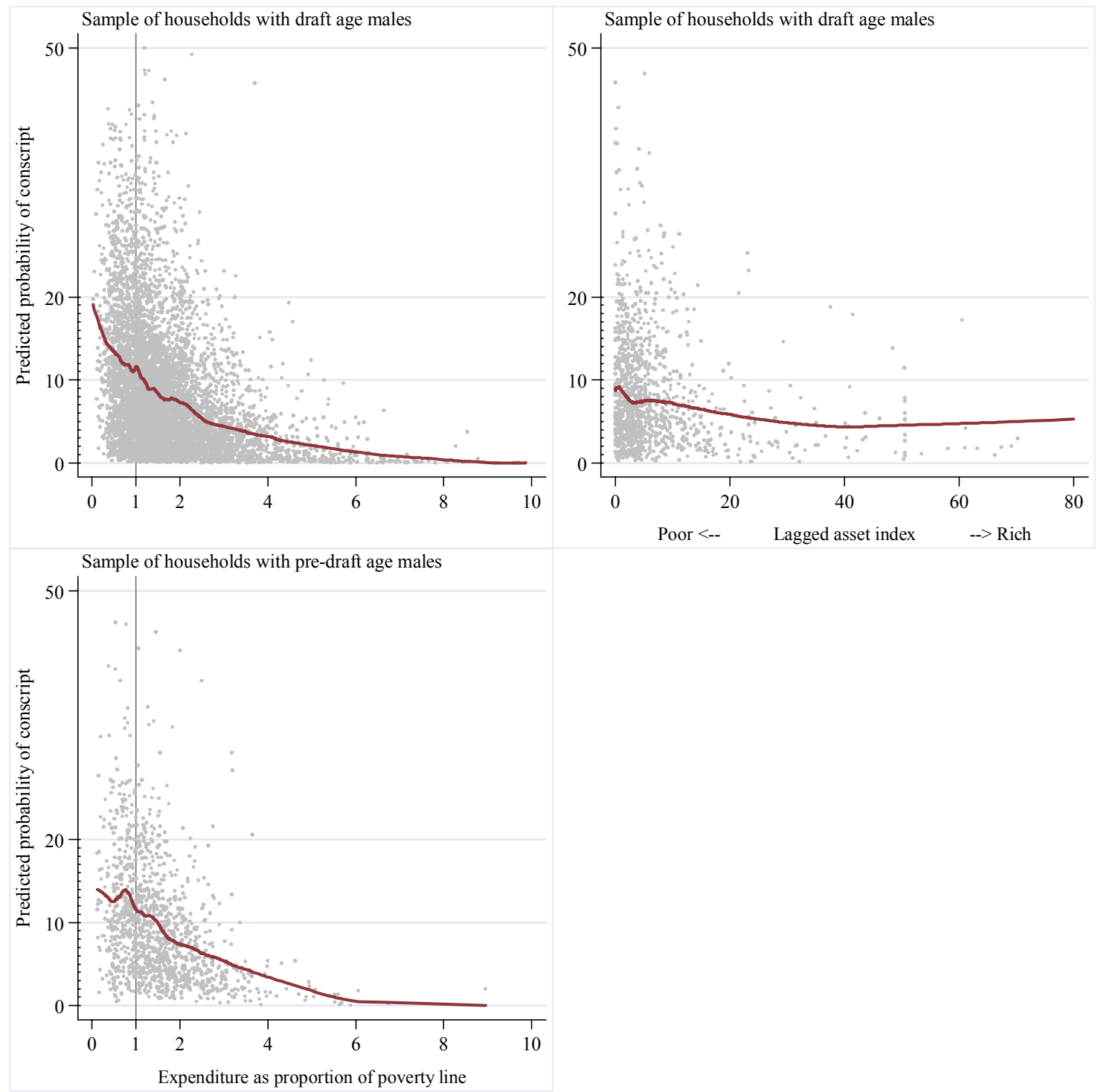

Figure 2: Predicted proportion of males age 18 to 27 in compulsory military service by household expenditure as a proportion of poverty line and by asset index. Locally weighted regression. 


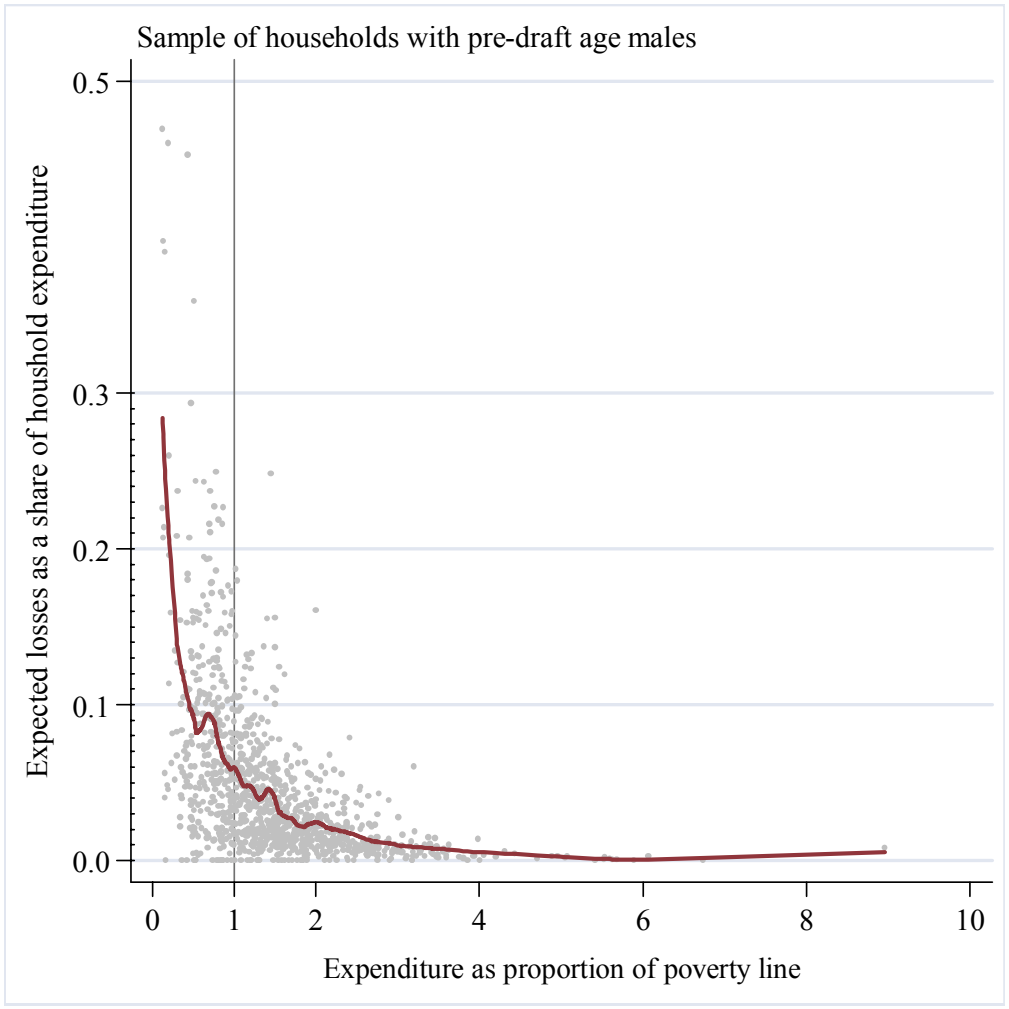

Figure 3: Simulated distribution of the expected losses from military service as a share of total household expenditure. Sample of households with a pre-draft age males. Locally weighted regression. 
Annex 2

Table A2: Instrumental variable regression of the FIML IV probit estimation

Per capita household consumption

IV regression

Household size

Coefficient

Std. Error

Household size2

$-0.796 * * * \quad 0.074$

Share of children 0-6 years old

Share of children 7-14 years old

Share of prime-age men

$0.057 * * * \quad 0.008$

Share of prime-age women

Share of elderly

Share of adults with primary education

Incomplete secondary

Complete secondary

Technical vocational

Secondary vocational

$-0.914 * * * \quad 0.240$

$-0.435 * \quad 0.215$

$0.070 \quad 0.173$

$-0.287 * \quad 0.141$

$-0.537 * \quad 0.229$

Incomplete higher

Complete higher and post-graduate

Head with primary education

Incomplete secondary

Complete secondary

Technical vocational

Secondary vocational

Incomplete higher

Reference

$\begin{array}{ll}-0.177 & 0.224\end{array}$

$0.480 * \quad 0.214$

$0.084 \quad 0.227$

$0.343 \quad 0.219$

$1.212 * * * \quad 0.239$

$0.912 * * * \quad 0.237$

Reference

$0.166 \quad 0.136$

$-0.050 \quad 0.131$

$0.214 \quad 0.142$

$0.199 \quad 0.132$

$0.080 \quad 0.175$

$0.179 \quad 0.144$

Complete higher and post-graduate

The son is a single child

Single parent household

$-0.107 *$

0.046

$-0.022$

0.060

$0.093 \quad 0.148$

Household members in the army

Household members with bad health

$-0.636 *$

0.277

Moscow and Saint Petersburg

$0.272 *$

0.116

Cities larger than $1 \mathrm{M}$

$-0.040$

0.078

Cities 500,000-1M

$0.142 * \quad 0.073$

Cities 250,000-499,900

$0.132 * \quad 0.061$

Cities 100,000-249,900

$0.427 * * *$

0.065

Towns 50,000-99,900

$0.393 * * *$

0.074

Towns 20,000-49,900

$0.308^{* * *}$

0.071

Towns with less than 20,000 , PGT

$0.304 * * *$

0.059

Villages

Share of young males in service

Reference

$-0.075^{*} \quad 0.036$

Regional unemployment rate

$-1.253 * * *$

0.248

Constructed assets index

$0.010 * * *$

0.001

$0.164 * * \quad 0.047$

Household owns a car

$-0.750 * * *$

0.175

Household owns a motobike

$-0.316^{* * *}$

0.068

Household owns a VCR

$0.378 * * *$

0.038

Household has extra property

$0.225 * * *$

0.042

Constant

$3.540 * * *$

0.242 